\title{
Liturgiasta käytäntöön: Kestävä kehitys ja julkiset ruokapalvelut
}

\author{
Helmi Risku-Norja ${ }^{1}$, Sirpa Kurppa ${ }^{2}$, Kirsi Silvennoinen ${ }^{2}$, Jonna Skinnari ${ }^{3}$ \\ ${ }^{1}$ MTT Taloustutkimus, 31600 Jokioinen, etunimi.sukunimi@mtt.fi \\ ${ }^{2}$ MTT Biotekniikka- ja elintarviketutkimus 31600 Jokioinen, etunimi.sukunimi@mtt.fi \\ ${ }^{3}$ HY Taloustieteen lait, Helsingin yliopisto, jonna.skinnari@helsinki.fi
}

\section{Tiivistelmä}

Julkisessa ruokahuollossa ja kouluruokailussa painotetaan erityisesti terveellisyyttä ja ravitsemusta. Nykyisin kuitenkin hyvän ravitsemuksen yhteiskunnallinen ja kansantaloudellinen merkitys tuntuu usein jäävän taloudellisuus- ja tehokkuusvaatimusten jalkoihin, kun haetaan välittömiä kustannussäästöjä. Kunnissa ruokahuollon toimijat ovat tietoisia ongelmista ja heillä on runsaasti ammatillista kiinnostusta kehittää toimintaansa kestävän kehityksen periaatteiden pohjalta.

Kestävä ruokahuolto ei ole pelkästään kunnan ruokahuoltohenkilöstön asia, vaan se tulisi istuttaa osaksi kunnan kokonaisvaltaista kehittämisstrategiaa. Koska resurssit ja käytännön toteutustavat vaihtelevat eri kunnissa, tulee ratkaisut räätälöidä tilanteen mukaan yhteistyössä paikallisten toimijoiden kanssa. Lähtökohtana ovat kestävän ruokahuollon kriteerit, joiden pohjalta tunnistetaan vahvuudet ja kehittämistarpeet omassa kunnassa ja asetetaan konkreettiset tavoitteet.

Tietoinen ruokakasvatus on avain nykyistä kestävämmän kunnallisen ruokahuollon toteuttamiseksi. Ruokakasvatus toteutuu parhaiten käytännössä, kun arkiruokailua kouluissa ja työpaikoilla kehitetään miellyttävänä sosiaalisen kanssakäymisen muotona. Ruokapalveluja voidaan kehittää vuorovaikutteisesti kohentamalla asiakkaille suunnattua tiedottamista ja rohkaisemalla asiakkaita toimintaan kestävämmän ruokakulttuurin puolesta. Ruokakasvatuksessa kannattaa kiinnittää huomiota nimenomaan kouluihin ja päiväkoteihin, sillä valtaosa kunnallisista ruokapalveluista kohdistuu näihin.

Kouluissa kuntien ruokahuoltostrategia ilmenee kouluruokailun toteutuksena. Valtakunnallinen perusopetuksen opetussuunnitelma painottaa kestävää kehitystä opetuksen arvoperustana, mutta ei anna valmiita toimintamalleja. Koulut voivat siten miettiä omien tarpeidensa pohjalta, miten kestävä kehitys kouluissa ilmenee. Kouluruokailun ja ruokakasvatuksen kytkeminen kiinteästi opetuksen tavoitteisiin sekä käytännön yhteistyö kouluruokalahenkilöstön kanssa ovat tapoja toteuttaa kestävän kehityksen kasvatusta ja istuttaa kestävä kehitys koulujen päivittäiseen toimintakulttuuriin.

Tämä tutkimus tuo kestävän kehityksen käsitteen arkipäivän käytäntöön tarkastelemalla, miten kestävä kehitys nykyisin otetaan huomioon kuntien julkisissa ruokapalveluissa ja minkälaisia kytkentöjä kouluruokailulla on kestävän kehityksen kasvatukseen ja opetuksen tavoitteisiin. Tutkimus perustuu kahden laajan kyselyn tuloksiin, joista toinen oli osoitettu kuntien ruokapalveluista vastaaville henkilöille ja toinen koulujen opettajille.

Asiasanat: kestävä ruokahuolto, kunnalliset ruokapalvelut, kouluruokailu, ruokakasvatus 


\section{Taustaa}

Kestävä kehitys on melko abstrakti käsite, ja se tuodaan usein esiin viittaamalla yleisesti Johannesburgin huippukokouksen ja vuosituhannen ekosysteemiarviointi asiakirjoihin. Näissä kestävä kehitys määritellään ihmisten ja luonnon hyvinvointina sekä sosio-kulttuurisena vuorovaikutuksena, joka turvaa hyvän elämän edellytykset nykyisille ja tuleville sukupolville kaikkialla maailmassa (WCDE 1987, UN 2005). Kestävän kehityksen uhkana ovat sekä paikallisesti että maailmanlaajuisesti kouriintuntuvat, mittavat sosiaaliset, kulttuuriset, taloudelliset ongelmat sekä ympäristönkuormitus.

Näin yleisellä tasolla ilmaistuna käsite jää usein hämäräksi, eikä yleviä tavoitteita pystytä toteuttamaan käytännössä. Usein kestävä kehitys ymmärretään pelkästään ympäristökysymyksenä (Ehrenfeld 2008), ja ympäristökysymyksistäkin tuodaan esiin nykyisin usein vain ilmastonmuutos. Sekaannusta lisää, että ”ympäristöllä” voidaan tarkoittaa joko fyysistä (luonnon) ympäristöä tai se ymmärretään laajemmin paitsi fyysisenä ympäristönä myös ihmisten välisenä sosiaalisen vuorovaikutuksen kenttänä (Hesselink et al. 2000, Wals 2001, OECD \& CERI 2006).

Kestävän kehityksen tutkimuksessa on viimeaikoina korostetusti tuotu esiin tarve sitoa tavoitteet sellaiseen käytännön toimintaan, joka on yhteiskunnan kannalta merkityksellistä ja joka voidaan linkittää maailmanlaajuisiin kestävän kehityksen haasteisiin (DeVries \& Petersen 2009, Scoullos 2009, van Ginkel 2009, Kauffman 2009). Tarkastelun tulee olla ongelmalähtöistä ja poikkitieteistä siten että siihen sisältyy vuorovaikutteinen oppiminen (Clark \& Dickson 2003, Luks \& Siebenhüner 2007, Tappeiner et al. 2007, Morgan \& Sonnino 2008).

Tässä tutkimuksessa kestävän kehityksen käsite tuodaan arkipäivän käytäntöön tarkastelemalla tavoitteita ja tavoitteiden toteutumista sekä julkisessa ruokahuollossa yleensä että erityisesti kouluruokailussa ja koulujen ruokakasvatuksessa. Tarkastelun kohteena ovat kuntien lakisääteiset ruokapalvelut, jotka kustannetaan julkisin varoin.

Kunnat ja valtio tuottavat pääosan julkisista ruokapalveluista itse (83 \%; HORECA 2007) tai kilpailuttavat palveluiden tuottajat. Lakisääteinen julkinen ruokapalvelu tuottaa yli puolet kaikista kodin ulkopuolella syötävistä aterioista. Väestöstä noin kolmasosa käyttää julkisia ruokapalveluja päivittäin, ja kaikki kansalaiset ovat niiden piirissä jossakin elämänsä vaiheessa (HORECA 2007). Julkisessa ruokahuollossa ja kouluruokailussa painotetaan erityisesti terveellisyyttä ja ravitsemusta (Eerola et al. 2004, Seppälä et al. 2004, SITRA 2007). Tämän kansalaiskasvatuksen tulokset näkyvät ruokailutottumusten vähittäisenä muutoksena mm. kasvisten ja vihannesten käytön lisääntymisenä sekä suolan ja kovien eläinrasvojen kulutuksen vähenemisenä.

Julkinen ruokahuolto on siten avainasemassa, kun halutaan edistää terveellisiä ruokatottumuksia ja vähentää sitä kautta terveydenhuollon kustannuksia. Sillä on myös kaikki edellytykset vaikuttaa ruokailutottumuksiin siten, että ne tukevat kestävää kehitystä muutenkin kuin terveyden edistämisen kautta. Julkinen ruokahuolto vaikuttaa myös volyyminsa kautta, sillä se muodostaa yhden ruoankuluttajaryhmän, jonka kulutuskäyttäytyminen on lakisääteisyytensä takia paljon ennustettavampaa kuin yksittäisten kuluttajien.

Julkisten ruokapalveluiden toimintaa on viime vuosina enenevästi tehostettu mm. kasvattamalla yksikkökokoa ja muodostamalla hankintarenkaita. (Mikkola 2009, MMM 2009). Sen valmistamat annosmäärät ovat kasvaneet; vuonna 2002 annosmäärä oli 420 miljoonaa, mutta nykyään yhteensä jo 440 
miljoonaa (Syyrakki 2009). Samanaikaisesti on julkisten keittiöiden lukumäärä vähentynyt liki 20 prosenttia, sillä vuonna 2002 niitä oli lähes 6000, vuonna 2007 keittiöitä oli enää 5002 (Finfood 2008).

Suomessa julkisten ruokapalveluiden tuotannossa ja kouluruokailussa korostuvat erityisesti terveellisyys ja ravitsemus, nykyisin entistä enemmän myös hinta. Onkin vaarana, että hintakilpailukyky ohittaa kestävän kehityksen tavoitteet ja että välittömiä kustannussäästöjä haettaessa unohdetaan hyvän ravitsemuksen yhteiskunnallinen merkitys ja sen tuomat pitkän tähtäimen kansantaloudelliset säästöt.

Tutkimuksessa haetaan vastausta, miten kestävä kehitys nykyisin otetaan huomioon kuntien julkisissa ruokapalveluissa ja miten se ylipäänsä ymmärretään. Kouluruokailun osalta selvitetään, miten ja missä määrin kouluruokailua nykyisin hyödynnetään alakoulujen perusopetuksessa, miten kouluissa toteutuu ruokakasvatus ja minkälaisia kytkentöjä sillä on kestävän kehityksen kasvatukseen.

Tavoitteena on löytää keinoja kestävämmän julkisen ruokahuollon toteuttamiseen sekä kouluruokailun hyödyntämiseen opetuksessa liittämällä se osaksi kestävän kehityksen kasvatusta.

\section{Tutkimuksen viitekehys}

Tässä tutkimuksessa julkisia ruokapalveluita tarkastellaan kestävän ruokahuollon kriteerien pohjalta. Kriteerit on määritelty niin, että ruoan merkitys yhteiskunnan, tuotannon, talouden, ympäristön, oman ja toisten maiden kulttuurin sekä terveyden ja ravitsemuksen kannalta tulee huomioonotetuksi.

Tarkastelu perustuu seuraaviin kriteereihin:

(1) Ruoan terveellisyys ja turvallisuus; tuotteiden tulee olla ravitsemuksellisesti hyviä ja terveellisiä ja hygieenisen laadun suhteen moitteettomia.

(2) Kulutuksen oikeudenmukaisuus ja huoltovarmuus; perusruokaturva on taattu kansallisesti ja globaalisti ja päätäntävalta on paikallisilla toimijoilla.

(3) Taloudellinen toteutettavuus; tuottajat saavat kohtuullisen korvauksen ja perusruoka on kohtuuhintaan kaikkien ulottuvilla.

(4) Ruoan kulttuurisuus ja omaleimaisuus; aterioiden perustana ovat kotimaiset ja lähellä tuotetut raaka-aineet, ja niissä heijastuvat sekä vuodenaikojen vaihtelu että oman alueen ruokaperinteet.

(5) Eettisyys; tuotanto täyttää eettiset normit koskien sekä työntekijöiden, tuotantoeläinten ja ympäristön hyvinvointia.

(6) Ekologinen kestävyys; tuotannon luonnonvaraperusta on turvattu ja ympäristökuormitus on hallinnassa.

(7) Esteettisyys; ruoka on maukasta, ateriakokonaisuudet suunnitellaan niin että väri-, tuoksu-. ja makumaailma sopivat yhteen ja se nautitaan kiireettä miellyttävässä ympäristössä. (Helenius 2003, Risku-Norja 2008, Patel 2008).

Samoja kriteereitä on tunnistettu myös vastuullisessa elintarviketaloudessa, missä keskeisiä tekijöitä ovat ympäristö, tuoteturvallisuus, ravitsemus, tuotannon eettisyys - erityisesti painotetaan työhyvinvointia ja eläinten hyvinvointia paikallisuus ja taloudellinen vastuu ja toteutettavuus (Forsman-Hugg et al. 2009). Samoin julkisten ruokapalvelujen laatukriteereihin on nostettu terveellisyyden ja turvallisuuden rinnalle ekologinen kestävyys, kulutuksen oikeudenmukaisuus sekä julkisten ruokapalvelujen kulttuurisuus (FCG Efeko Oy 2009).

Kestävä kehitys edellyttää tavoitteellista toimintaa ja on siten määritelmällisesti normatiivista ja muutokseen tähtäävää (transformatiivista). 
Tutkimuksessa on sen vuoksi tarkastelunäkökulmana paitsi käytännön toimintatapojen muutos, myös julkisten ruokapalvelujen merkitys kansalaiskasvatuksessa.

\section{Aineisto ja menetelmät}

Tutkimusaineisto käsittää kahden loppukesällä 2008 tehdyn laajan kyselyn tulokset. Ensimmäinen kysely oli osoitettu kuntien ruokapalvelutoiminnasta vastaaville henkilöille ja se lähetettiin kaikkiin Manner-Suomien kuntiin. Kyselyn avulla kerättiin perustietoa kuntien ruokapalveluista sekä ruokapalvelutoimijoiden kokemuksia ja kehittämisajatuksia. Tarkoituksena oli selvittää, miten kestävä kehitys nykyisin otettu huomioon kuntien julkisissa ruokapalveluissa, miten kestävä kehitys ylipäänsä ymmärretään kunnallisessa ruokahuollossa ja miten julkinen ruokahuolto voi sitä edistää. Tähän kyselyyn vastasi 116 kuntaa ja vastausprosentti oli 29.

Toinen kysely lähetettiin suomen- ja ruotsinkielisenä kaikille Suomen alakouluille. Sen avulla haluttiin selvittää, miten ja missä määrin kouluruokailua hyödynnetään opetuksessa, minkälaista yhteistyötä koulun sisällä on opetus- ja kouluruokahenkilöstön kesken ja missä määrin koulun ulkopuolella tapahtuva opetus, erityisesti yhteistyö maatilojen kanssa, tukee ruokakasvatusta. Kyselyyn saatiin yhteensä 814 vastausta $(747+67)$ ja vastausprosentti oli 31 .

Kyselyjen lisäksi käytiin läpi Internetistä saatavissa olevat kuntakohtaiset opetussuunnitelmat sekä Kohti hiilineutraalia kuntaa -hankkeeseen osallistuvien kuntien (Kuhmoinen, Mynämäki, Padasjoki, Parikkala ja Uusikaupunki) kotisivut ja etsittiin mahdollisia mainintoja kunnallisen ruokahuollon ja kouluruokailun kytkennästä kestävään kehitykseen.

Vastauksista on koottu numeeriset perustiedot ja tuloksia tarkastellaan prosentuaalisen jakauman perusteella. Vastauksia tarkasteltaessa on kiinnitetty huomiota mahdollisiin eroihin eri kuntatyyppien välillä, koulukyselyn osalta myös mahdollisiin eroihin suomen- ja ruotsinkielisten koulujen välillä. Kunnat jaoteltiin käyttämällä Tilastokeskuksen neljän kuntatyypin luokittelua: syrjäinen maaseutu, ydinmaaseutu, kaupunkien läheinen maaseutu ja kaupunki vuoden 2007 tietoihin perustuen (Tilastokeskus 2008). Aineistojen käsittelyssä on kiinnitetty erityisesti huomiota vapaasanaisten, avointen vastausten laadulliseen tarkasteluun. Vastausten sisältöanalyysin lähtökohtana ovat kestävän ruokahuollon kriteerit. Kuntatyyppien välisiä eroja on analysoitu myös ei-parametrisen varianssianalyysin avulla.

Koska kyselyt olivat hyvin laajoja, kaikkiin kohtiin ei aina ole vastattu, joten vastaajamäärä vaihtelee kysymyskohtaisesti. Vastanneet kunnat sijoittuvat kuitenkin tasaisesti eri puolelle Suomea, ja kunnat ovat väkilukunsa ja kuntatyyppinsä mukaan edustettuina varsin tasaisesti eri kuntaluokista, mikä osaltaan parantaa tulosten yleistettävyyttä. Keskeiset asiat molempien kyselyjen vastauksista on julkaistu erikseen (Risku-Norja et al. 2009a). Tulokset kaikista kysymyksistä on lisäksi koottu omiin raportteihinsa (Risku-Norja et al. 2009b ja Risku-Norja et al. 2009c). Osasta aineistoa on valmistumassa myös opinnäytetyö Helsingin yliopistossa Taloustieteen laitoksella (Skinnari 2009). Tutkielmassa tarkastellaan kestävän kehityksen tavoitteiden toteutumista julkisissa ruokahankinnoissa, ja siinä kiinnitetään erityisesti huomiota elintarvikehankintojen kilpailutukseen sekä kriteereihin, joiden perusteella virkamiehet päättävät julkisista ateriahankinnoista 


\section{Tulokset}

Kuntien ruokapalvelujen toteutuksessa kestävän ruokahuollon kriteerit on vaihtelevasti otettu huomioon, vaikkakaan yhteyttä kestävään kehitykseen ei välttämättä tuoda julki. Julkisten ruokapalvelujen yhteiskunnallinen merkitys on kansalaisten ruokaturvan ja hyvinvoinnin edistämisessä. Ravitsemussuositukset ovat itsestään selvä lähtökohta, ja oikeudenmukaisuus ja tasapuolisuus toteutuvat lakisääteisyyden kautta. Nämä asiat tuodaan vastauksissa esiin, mutta niitä ei yhdistetä millään tavoin kestävän kehitykseen.

Sekä kouluissa että kunnissa käsitys kestävästä kehityksestä painottuu ympäristöasioihin, kun taas taloudelliset seikat nähdään pikemminkin esteenä kestävän kehityksen tavoitteiden toteutumiselle kuin osana tavoitteita. Kotimaista ja lähellä tuotettua ruokaa arvostetaan ja toivotaan sen lisääntyvän; etenkin lähellä tuotettuja sesonkituotteita pyritään suosimaan, joskin hankintojen keskittäminen ja kilpailuttaminen hankaloittaa niiden käyttöä. Lähiruoka liitetään kestävään kehitykseen sekä kuljetustarpeen vähenemisen että ruokakulttuurin ja yhteisöön liittyvien asioiden kautta. Kulttuurinen ulottuvuus näkyy myös erilaisten juhlapäivien huomioonottamisena. Eettinen puoli näkyy huolena ruokapalveluhenkilöstön hyvinvoinnista ja jaksamisesta, mutta globaalia eettisyyttä edustavalla Reilulla kaupalla ei ole toiminnassa juurikaan sijaa. Myös esteettisiin kysymyksiin, ruokailutilojen viihtyvyyteen ja aterian tarjolle panoon sekä itse ruokailutilanteeseen, kiinnitetään aika vähän huomiota.

Koulujen vastauksissa kouluruokailun yhteys kestävään kehitykseen mainitaan vastauksissa aika harvoin. Opetussuunnitelmissa se liitetään vahvasti terveys, ravitsemus- ja tapakasvatukseen. Jos kouluruokailulla ja/tai maatilayhteistyöllä nähdään yhteyksiä opetuksen tavoitteisiin, mainitaan ne lähinnä ympäristö- ja luonnontiedon opetuksen yhteydessä. Kolme neljästä vastanneista kouluista käy oppilaiden kanssa marjassa ja/tai sienessä ja maatilavierailut muodossa tai toisessa ovat myös hyvin yleisiä. Sen sijaan ruoan valmistukseen tai jakeluun oppilaat eivät yleensä osallistu, mutta puolet vastanneita kouluista ilmoitti oppilaiden osallistuvan ruokalan siivoukseen. Jos koulussa on oma keittiö, käytetään sitä eri tavoin hyväksi opetuksessa. Keittiöhenkilökunta on mukana ohjaamalla oppilaita näissä tilanteissa samoin kuin juhlien ja teemapäivien suunnittelussa ja toteutuksessa. Laajempi ruokakasvatuksen käsite ei ole kuitenkaan välttämättä tuttu eikä sitä ole mainittu nykyisessä perusopetuksen opetussuunnitelmassakaan. Myös kestävän kehityksen kasvatus käsitetään edelleen usein suppeampana ympäristökasvatuksena, jolloin painotukset ovat kierrätyksessä, energian ja materiaalien säästämistavoitteissa sekä ympäristökuormituksen vähentämisessä yleisemminkin.

\section{Pohdintaa}

Julkisia ruokapalveluita kehitettäessä voidaan soveltaa kestävän kehityksen tutkimuksen periaatteita, joita ovat ongelmalähtöisyys, normatiivisuus, poikkitieteisyys, toimijatahojen vuorovaikutteinen oppiminen ja kytkeytymineen maailmanlaajuisiin kestävän kehityksen kysymyksiin. Ongelmalähtöisyys ja normatiivisuus toteutuvat, kun määritellään, mitä kestävä kehitys tarkoittaa kunnallisten ruokapalvelujen yhteydessä, ja kehittämistavoitteet asetetaan niin että toiminta tukee kestävän kehityksen tavoitteita. Kulutuksen oikeudenmukaisuutta ja ruokaturvaa koskevat kysymykset tuovat toimintaan globaalin näkökulman, kun julkiset ruokapalvelut nähdään osana perusruokaturvaa, jossa päätäntävalta on 
paikallisilla toimijoilla. Poikkitieteisyys (transdisciplinarity) toteutuu, kun ongelmaa lähestytään muodostamalla yhteinen viitekehys eri tieteenalojen kesken ja tietoa tuotetaan ja tavoitteet asetetaan vuorovaikutuksessa yhteiskunnan muiden toimijaryhmien kanssa; poikkitieteisyys ei siten ole sama kuin tieteidenvälisyys (interdisciplinarity), mikä tarkoittaa eri tieteenalojen välisten rajojen ylittämistä tiedeyhteisön sisällä (Bruun et al. 2005). Vuorovaikutteinen oppiminen toteutuu, kun kestävästä kehityksestä tulee itseohjautuvaa niin, että toimintaa arvioidaan ja toimintatapoja ja tavoitteita tarkistetaan tilanteiden muuttuessa ja uuden tiedon valossa.

Ruokahuollon toteutus ja resursointi sekä väestöpohja vaihtelevat kuntakohtaisesti, ja myös ruoantuotannon edellytykset vaihtelevat eri puolilla Suomea. Ratkaisut täytyy sen vuoksi rakentaa yhteistyössä paikallisen toimijaverkoston kanssa ja ne täytyy räätälöidä kunnan tarpeita silmälläpitäen. Tämä edellyttää laaja-alaista ymmärrystä ruokahuollon toimijaverkostosta ja toimintaympäristöstä sekä erilaisista vuorovaikutussuhteista ja kokonaisuuteen myötävaikuttavista tekijöistä. Kehittämisen lähtökohtana ovat kestävän ruokahuollon kriteerit, joiden pohjalta tunnistetaan vahvuudet ja kehittämistarpeet omassa kunnassa, ja asetetaan konkreettiset tavoitteet. Toimijoilla tulee siis olla yhteinen ja kokonaisvaltainen näkemys siitä, mitä kestävä ruokahuolto tarkoittaa. Yhteinen käsitys muodostuu keskinäisessä vuorovaikutuksessa avoimen ja selkeän viestinnän välityksellä. Viestintä käsittää alan toimijoiden keskinäisen vuoropuhelun, mutta myös vuoropuhelun alan toimijoiden, neuvontajärjestöjen edustajien ja tutkijoiden välillä.

Asiakkailta saatu palaute on eräs tärkeimpiä kriteereitä ruokapalvelujen kehittämisessä, mutta nykyisin asiakkaille kerrotaan kuitenkin hyvin vähän ruoan alkuperästä, ravintosisällöstä, tuotannon ympäristövaikutuksista tai tuottajista (Risku-Norja et al. 2009a,c). Kun ruokakulttuuria halutaan muuttaa kestävämpään suuntaan, tarvitaan tietoista ruokakasvatusta, joka tähtää käsitteen ja toiminnan muutokseen niin että edistetään ihmisten ja ympäristön hyvinvointia sekä sosiaalista oikeudenmukaisuutta. Asiakkaille suunnattu tiedottaminen on osa kansalaisten ruokakasvatusta. Ruokakasvatus ei kuitenkaan ole pelkästään tietoa ravitsemuksesta ja terveydestä. Sen kautta vaikutetaan myös arvoihin ja asenteisiin ottamalla mukaan esteettiset, eettiset, kulttuuriset ja sosiaaliset lähestymistavat, jotta voidaan muodostaa kokonaisvaltainen käsitys kestävän kehityksen eri ulottuvuuksista (Spigarolo \& Donegani 2009). Ruokakasvatus toteutuu parhaiten käytännössä, kun arkiruokailua kehitetään yhdessä asiakkaiden kanssa miellyttävänä sosiaalisen kanssakäymisen muotona tarjoamalla myönteisiä kokemuksia, tietoa ja tarinoita, tuomalla esiin ruoan yhteiskunnallisia kytkentöjä ja yhteisöllistä merkitystä.

Valtaosa kuntien ruokapalveluista koskee kouluja. Kun lisäksi monet ruokakäyttäytymisen mallit luodaan varhaisella iällä, tulisi kunnallisen ruokahuollon kansalaiskasvatuksessa kiinnittää enemmän huomiota kouluihin ja kehittää vuorovaikutusta ja yhteistyötä kouluruokailuun liittyvän ruokakasvatuksen puitteissa. Kouluissa kunnan ruokahuoltostrategia ilmenee kouluruokailun toteutuksena ja kouluruokailulla on keskeinen osa ruokakasvatuksessa. Kouluruokailua voidaan hyödyntää opetuksessa koko koulu -lähestymistavan pohjalta ("whole school approach", Morgan \& Sonnino 2008). Tämä tarkoittaa, että kouluruokailu kytketään kiinteästi opetuksen tavoitteisiin oppiaineissa ja aihekokonaisuuksissa ja että pyrkimys kestävään kehitykseen ilmenee myös kouluruokailun käytännön toteutuksessa. Tavoitteet tulisi kirjata myös 
opetussuunnitelmaan. Koko kouluyhteisöllä on merkitystä kasvatuksen onnistumisessa, joten opettajien lisäksi myös muun kouluhenkilökunnan osallistuminen on tärkeää. Ruokailun pitäisikin olla ilmaista koko henkilökunnalle sekä siihen tulisi varata riittävästi työaikaa. Oppilaiden oma osallistuminen on myös tärkeää ja sitä tulisi kehittää siten että ruokaan ja ruokailuun muodostuisi kestävä arvomaailma.

Kestävä ruokahuolto ei ole pelkästään kunnan ruokahuoltohenkilöstön asia, vaan on tärkeätä istuttaa se osaksi kunnan kokonaisvaltaista kehittämistä, jossa kuntastrategia on keskeinen työväline. Kun kestävä ruokahuolto kirjataan kuntastrategiaan, sille asetetaan vuosittain konkreettiset tavoitteet ja mietitään myös toteutuksen resursointi. Kehittäminen muuttuu pitkäjänteiseksi, kun tavoitteiden toteutumista seurataan ja arvioidaan.

\section{Viitteet}

Bruun, H., Hukkinen, J., Huutoniemi, K. \& Klein, J.T. 2005. Promoting interdiscipolinary reearch: The case of the Academy of Finland. Helsinki: Edita. Publications of the Academy of Finland 8/05. $206 \mathrm{~s}$.

Clark, W.C. \& Dickson, N.M. 2003. Sustainability science: the emerging research program. Proceedings of the National Academy of Sciences of the United States of America 100, 14: 8059-8061.

DeVries, B. \& Petersen, A. 2009. Conceptualizing sustainable development. Ecological Economics; Ecological Economics 68, 4: 1006-1019.

Eerola, A., Hasunen, K., Hautamäki, O., Keskinen, H., Nordblad, A. \& Pietinen, P. 2004. Terve kouluympäristö - koululaisten ravitsemus ja suun terveys. Seminaari 9.12.2003. Sosiaali- Ja Terveysministeriön Monisteita, 2004:14.

Ehrenfeld, J. 2008. Sustainability by Design: A Subversive Strategy for Transforming our Consumer Culture. New Haven: Yale University Press. 233 s.

Finnfood 2008. Tietohaarukka 2008. Tilastotietoa elintarvikealasta.

http://www.ruokatieto.fi/Suomeksi/Ruokafaktaa/Tietohaarukka

Forsman-Hugg , S. , Katajajuuri, J-M., Paananen, J., Pesonen, I., Järvelä, K. \& Mäkelä, J. 2009. Elintarvikeketjun vastuullisuus. Kuvaus vuorovaikutteisen sisällön rakentamisen prosessista. Maa- ja elintarviketalous 140. MTT: Helsinki.

FCG Efeko Oy 2009. Lisäarvoa laatutyöstä - Julkisten ruokapalvelujen laatukriteerit. http://www.laatuketju.fi/laatuketju/www/fi/hankkeet/2009/julkiset_ruokapalvelut.php

Helenius J. 2003. Eettinen elintarviketuotanto - kotimainen ja kansainvälinen näkökulma. http://www.eettinenfoorumi.org/foorumit_6 helenius.shtml.

Hesselink, F., van Kempen, P.P. \& Wals, A.E.J. 2000. ESDebate: International on-line debate on education for sustainable development. IUCN, Gland.

HORECA 2007. Horeca rekisteri: kodin ulkpuolella syötyjen annosten määrä kasvoi. The Nielsen Company. Espoo, Fnland: 1-8.

Kauffman, J. 2009. Advancing sustainability science: report on the International Conference on Sustainability Science (ICSS) 2009. Sustainability Science 4, 2: 215-232.

Luks, F. \& Siebenhüner, B. 2007. Transdisciplinarity for social learning? The contribution of the German socio-ecological research initiative to sustainability governance. Ecological Economics 63, 2-3: 418-426.

Mikkola, M. 2009. Shaping professional identity for sustainability: Evidence in Finnish public cateringng. Appetite 53, 1: 56-65.

MMM 2009. Selvitys kansallisen ruokastrategian taustaksi http://www.mmm.fi/attachments/elintarvikkeet/5HKe7TYp2/Ruokastrategia_taustaselvitys.pdf_UU SI.pdf. Maa- ja metsätalousministeriö. http://www.mmm.fi/attachments/elintarvikkeet/5HKe7TYp2/Ruokastrategia_taustaselvitys.pdf_UU SI.pdf

Morgan, K. \& Sonnino, R. 2008. The School Food Revolution. Public Food and the Challenge of Sustainable Development. London: Earthscan. $231 \mathrm{~s}$.

OECD \& CERI 2006. Environment and School Initiatives - 20 years of innovation and action research in Environmental education and Education for Sustainable Development. http://www.ensi.org/. 
Patel, Raj, 2008. Stuffed and Starved: The Hidden Battle for the World Food System. Portabello Books, UK. $416 \mathrm{~s}$.

Risku-Norja, H. 2008. Kestävää kehitystä julkisiin ruokapalveluihin. Maaseudun tiede 65, 4(15.12.2008): 13

Risku-Norja, H., Kurppa, S., Silvennoinen, K., Nuoranne, A., Skinnari, J. 2009a. Julkiset ruokapalvelut ja ruokakasvatus: arjen käytäntöjen kautta kestävään ruokahuoltoon. MTT Kasvu (toimitettavana)

Risku-Norja, H., Nuoranne, A. Silvennoinen, K. 2009b. Ruokakasvatus osana kestävän kehityksen kasvatusta koulujen opetussuunnitelmissa ja arjen käytännöissä. SEED-hankkeen raportti 30.6.2009 MTT.

Risku-Norja, H., Skinnari, J., Nuoranne, A., Silvennoinen, K 2009c. Kestävät julkiset ruokapalvelut kuntien toiminnoissa. PubCat-hankkeen raportti 15.7.2009,MTT

Scoullos, M. 2009. The framework of Sustainable Development (SD) and Education for Sustainable Development in Higher Education. Halfway through the UN-decade for Education for Sustainable Development Lessons learned and missions to follow in higher education. 22.23.10.2009, Turku. Baltic University Program. Konferenssiesitys. http://www.bup.fi/index.php/Event-Reports-Protocols/conference-presentations.html

Skinnari, J. 2009. Julkisen sektorin ruokapalveluhankintojen kestävyys. Taloustieteen laitos. Helsingin yliopisto (tarkastettavana).

Spigarolo, R. \& Donegani, G. 2009. Practice of organic food in Italian schools. Mikkola, M., Mikkelsen, B.E. \&Roos, G. (toim.): Like whjat uou get? Is it good for you? Organic food, health and sustainable development in schools. 27-33.

Seppälä, R., Levo, J. \& Työppönen, K. (toim.) 2004. Ruokapalvelumarkkinat 2004. Julkisten ruokapalvelujen nykytila ja kehittämisnäkymät. Helsinki: Efektia.

SITRA 2007. Ympäristöohjelma 2005 - 2007. http://www.sitra.fi/fi/Ohjelmat/PaattyneetOhjelmat/ymparisto/ymparisto.htm

Syyrakki, S. 2009. Päättäjän opas, Lähituottajat ja kunnalliset ruokapalvelut, http://www.tkk.utu.fi/extkk//ruokasuomi/oppaat_paattajan_opas_2009.pdf

Tappeiner, G., Tappeiner, U. \& Walde, J. 2007. Integrating disciplinary research into an interdisciplinary framework: A case study in sustainability research. Environmental Modeling and Assessment 12, 4: 253-256.

Tilastokeskus 2008. Maaseutuindikaattorit. http://www.stat.fi/tup/tilastotietokannat/index_en.html

UN 2005. Johannesburg Plan of Implementation. http://www.un.org/esa/sustdev/documents/WSSD_POI_PD/English/POIToc.htm

van Ginkel, H. 2009. Why Universities need to change ... and how? Blomqvist, E. \& P. Lindroos (eds.). Halfway through the UN-decade for Education for Sustainable Development Lessons learned and missions to follow in higher education. 22.-23.10.2009, Turku. Baltic University Program. Konferenssiesitys. http://www.bup.fi/index.php/Event-Reports-Protocols/conferencepresentations.html

Wals, A. 2001. Education for sustainable development: critique, promise and guide post. Development of Agenda 21 for Education in the Baltic Sea region, Karlskrona, Sweden on June 18-19, 2001. http://www.baltic21.org/Meetings/new/education/EDU2_appendix3.pdf.

WCDE 1987. Report of the World Commission on Environment and Development http://www.un.org/documents/ga/res/42/ares42-187.htm 